\title{
Unconjugated Lymphoma Ig Id
}

National Cancer Institute

\section{Source}

National Cancer Institute. Unconjugated Lymphoma Ig Id. NCI Thesaurus. Code C2821.

A vaccine consisting of lymphoma-specific immunoglobulin that is not conjug ated to a carrier molecule. Vaccination with unconjug ated lymphoma Ig Id may stimulate the host immune system to mount a cytotoxic $T$ lymphocyte $(C T L)$ response against lymphoma cells, resulting in decreased tumor growth. ( $\mathrm{NCl04)}$ 